\title{
Synthesis of a BACE1 Inhibitor
}

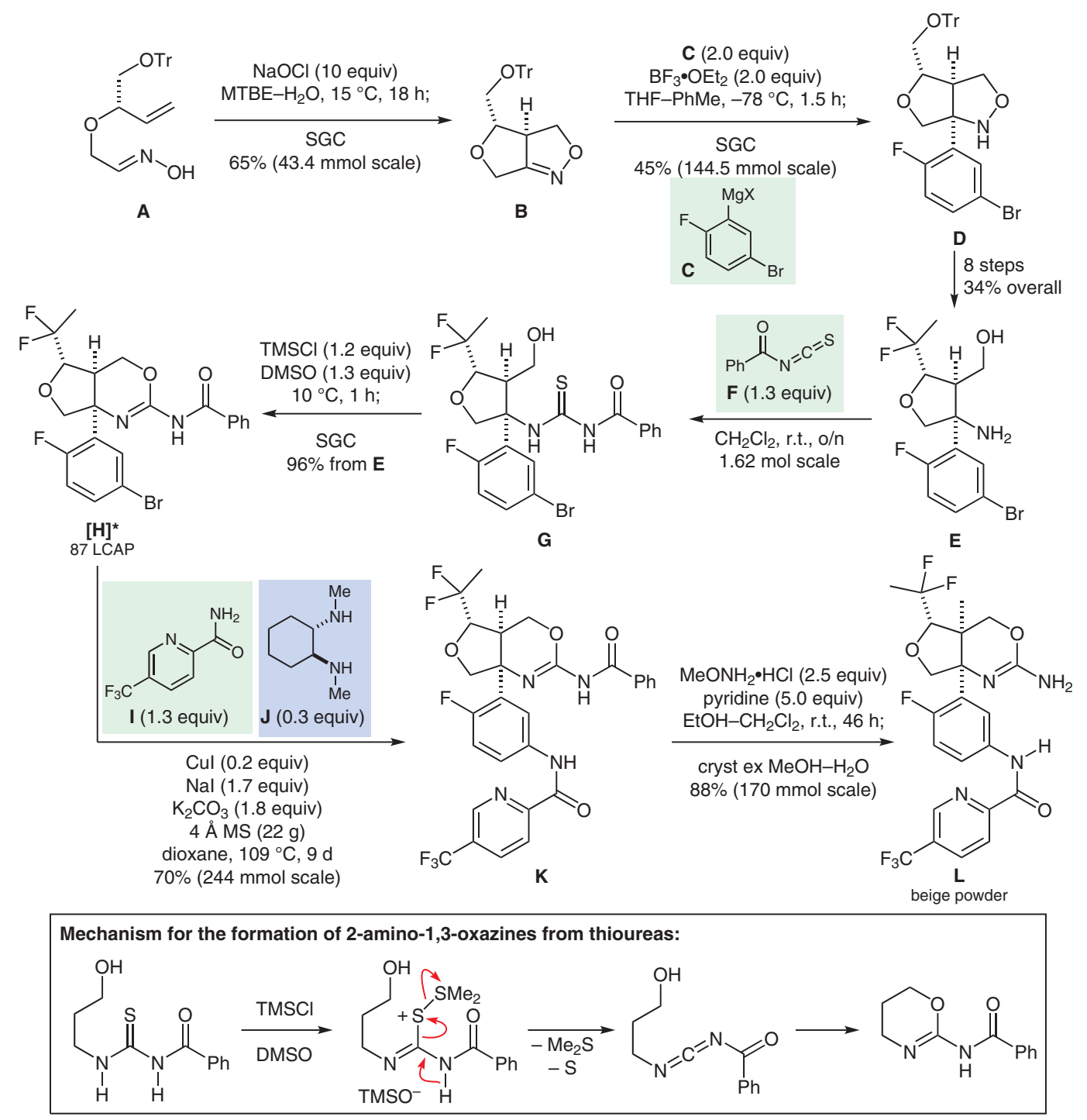

Synthesis of Natural

Products and

Potential Drugs

Key words

BACE1 inhibitor

Alzheimer's disease

thioureas

2-amino-1,3-

oxazines

$\mathrm{N}$-arylation

copper(I) iodide

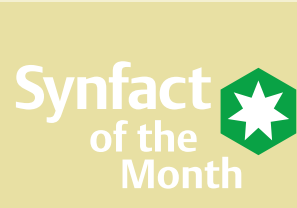

Significance: The target molecule $\mathbf{L}$, an inhibitor of the $\beta$-amyloid cleaving enzyme 1 (BACE1), is of interest for the treatment of Alzheimer's disease. A synthesis of $\mathbf{L}$ was recently disclosed (US 2019 $0106434 \mathrm{~A} 1$ ) that features the reaction of $\mathrm{N}$-benzo$\mathrm{yl}$ thiourea $\mathrm{G}$ with $\mathrm{TMSCl}$ in DMSO at $10{ }^{\circ} \mathrm{C}$ to give 2-amino-1,3-oxazine I in 96\% yield. Eight simpler examples of the cyclization reaction are described.
Comment: The key cyclization reaction $\mathbf{G} \rightarrow \mathbf{H}$ can be performed by reacting either $\mathrm{TMSCl}$ or $\mathrm{HCl}$ with DMSO to form sulfonium salts, which can activate the thiourea, enabling the elimination of dimethyl sulfide and sulfur to form a carbodiimide intermediate, which cyclizes to form the 2-amino-1,3-oxazine. The overall yield for the 18-step synthesis is $7.5 \%$ 